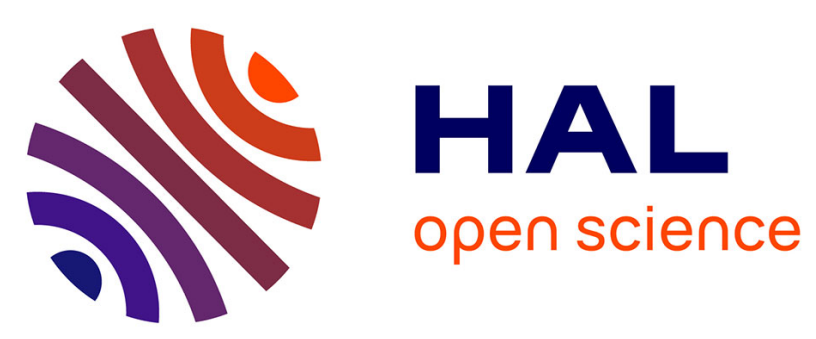

\title{
Economics of species change subject to risk of climate change and increasing information: a (quasi-)option value analysis
}

\author{
Marielle Brunette, Sandrine Costa, Franck Lecocq
}

\section{To cite this version:}

Marielle Brunette, Sandrine Costa, Franck Lecocq. Economics of species change subject to risk of climate change and increasing information: a (quasi-)option value analysis. Annals of Forest Science, 2014, 71 (2), pp.279-290. 10.1007/s13595-013-0281-0 . hal-01098396

\section{HAL Id: hal-01098396 https://hal.science/hal-01098396}

Submitted on 24 Dec 2014

HAL is a multi-disciplinary open access archive for the deposit and dissemination of scientific research documents, whether they are published or not. The documents may come from teaching and research institutions in France or abroad, or from public or private research centers.
L'archive ouverte pluridisciplinaire HAL, est destinée au dépôt et à la diffusion de documents scientifiques de niveau recherche, publiés ou non, émanant des établissements d'enseignement et de recherche français ou étrangers, des laboratoires publics ou privés.

$$
\text { Copyright }
$$




\title{
Economics of species change subject to risk of climate change and increasing information: a (quasi-)option value analysis
}

\author{
Marielle Brunette • Sandrine Costa • Franck Lecocq
}

Received: 3 October 2012 / Accepted: 4 March 2013 /Published online: 5 April 2013

(C) INRA and Springer-Verlag France 2013

\begin{abstract}
- Context In the context of climate change, several forest adaptation options have to be advocated such as a shift to more resistant species.

- Aims We provide an economic analysis of timber species change as a tool for adapting forests to climate change.

- Methods We use the framework of cost-benefit analysis, taking uncertainty into account both exogenously (sensitivity analysis) and endogenously [(quasi-)option value calculations]. We apply the method to assess the economic rationale for converting Norway spruce stands to Douglasfir in the French Black Mountain.

- Results We find that the Douglas-fir conversion is land expectation value (LEV) maximizing under a wide range of a priori (subjective) probabilities attached to high mortality of Norway spruce under climate change (for probabilities higher than 0.25-0.31). If information about the impacts of climate change is expected to increase over time, and given the large sunk costs attached to conversion, a delay strategy may be preferable to transition and to status quo when the impacts of climate change on Norway spruce mortality are
\end{abstract}

\section{Handling Editor: Marc Hanewinkel}

Contribution of the co-authors Marielle Brunette: analysis in case of risk aversion, management of writing process and revision of the manuscript.

\footnotetext{
M. Brunette $(\bowtie)$

INRA, UMR 356 Economie Forestière, 14 rue Girardet,

54000 Nancy, France

e-mail: Marielle.Brunette@nancy.inra.fr

S. Costa

INRA, UMR 1110 MOISA, 34000 Montpellier, France

F. Lecocq

CIRED, UMR 8568 CNRS, ENPC, CIRAD, EHESS,

AgroParisTech, 94736 Nogent/Marne, France
}

sufficiently ambiguous. In such cases, getting information earlier increases the LEV by $€ 5-60 /$ ha.

- Conclusion Beyond the specifics of the case study, this paper suggests that quasi-option value is a relevant tool to provide insights to forest owners dealing with adaptation decisions in the context of climate change.

Keywords Adaptation to climate change $\cdot$ Cost-benefit analysis · (Quasi-)option value · Forest conversion

\section{Introduction}

Climate change impacts on forest ecosystems are expected to be significant. In France, for example, climatologists expect more intense precipitations during winter and longer droughts during summer, as mean temperatures increase by $+1.5^{\circ} \mathrm{C}$ to + $5{ }^{\circ} \mathrm{C}$ depending on the climate scenario (IPCC 2007). Such changes in the climate could impact the phenology and reproduction of trees, their growth, as well as the distribution and prevalence of risks. In fact, the implications of climate change for different species in various contexts have also been extensively explored, for example, with Scots pine (Kellomäki et al. 2007), Norway spruce (Bricenõ-Elizondo et al. 2006), oak (Becker et al. 1994), beech (Bolte et al. 2007) and Douglas-fir (Nigh 2006).

Unlike managers in many other sectors, forest managers should already include climate change in the process of decision-making. This is because many forest management decisions have long-term implications, as typical rotation lengths of major commercial tree species range between 4 and 15 decades, and because these decisions, such as selecting species or stand structure, are largely irreversible. The choice of a species for a given stand, for example, can only be overturned by cutting trees and starting over, which would entail high sunk costs. Moreover, risk preferences are known to be 
an important determinant of forest owners' decisions (Lönnstedt and Svensson 2000). As a result, a wide range of solutions have already been proposed to adapt forest management practices to climate change: a shift from monoculture to mixed stand (Shou et al. 2012), planting alternate genotypes or new species (Spittlehouse and Stewart 2003; Carina and Keskitalo 2011), sanitation thinning (Spittlehouse and Stewart 2003; Guariguata et al. 2008), increasing the amount of salvage logging (Spittlehouse and Stewart 2003), changing rotation length (Spittlehouse and Stewart 2003; Seidl et al. 2011) and planning landscapes to minimize the spread of insects and diseases (Spittlehouse and Stewart 2003), or shifting to climatically more robust and/or shorter rotation species (Spittlehouse and Stewart 2003; Carina and Keskitalo 2011).

Yet while the proposed adaptation options have often been analyzed from a biophysical point of view, economic assessments remain scarce. Hanewinkel et al. (2010) evaluate the economic impact of a predicted shift from Norway spruce to European beech in Germany. Similarly, in a comparison of several management options to balance mitigation and adaptation considerations in a large Norway spruce-dominated German forest, Yousefpour et al. (2010) argue that the best option is to introduce beech seedlings into the conversion regimes combined with an early reduction of standing volume. More recently, Hanewinkel et al. (2012) evaluate the loss due to biome shift in European forest in response to climate change. They show that the expected value of European forest land will decrease owing to the decline of economically valuable species in the absence of effective countermeasures. For instance, they found that by 2100 , this loss varies between $14 \%$ and $50 \%$ of the present value of forest land in Europe, and may total several hundred billion Euros. These papers provide important insights into the costs and benefits of several adaptation measures, but they do not take into consideration two key characteristics of forest managers' decision problems under climate change.

- First, major uncertainties still prevail as to what the implications of climate change for specific forest ecosystems really are.

- Second, knowledge of climate change impacts and the advantages and limitations of adaptation options is likely to increase over time. As time goes by, more information on the real climate change and on its impact on forest ecosystems will become available. In addition, research and development can be expected to increase the body of knowledge and reduce uncertainties.

In other words, one of forest managers' decision problems is to make irreversible decisions under uncertainty and increasing information. Here, the question is no longer just which adaptation measure is best, but also when it should be implemented. Waiting for more information becomes an option that has to be assessed. In fact, many types of decisions share the above characteristics, and the canonical problem of irreversible choices under uncertainty and increased information has been extensively studied in the economic literature, using the concept of (quasi-)option value (QOV) developed by Arrow and Fisher (1974) and Henry (1974). This framework also allows one to evaluate the benefits of getting information earlier, with implications both for private decision-making (if private agents can purchase information) and for public policies (for example, to evaluate the potential benefits of increased R\&D).

Mitigation decisions on climate change have been extensively analyzed within this framework (see for instance, Peterson 2006, for a survey, or Ha-Duong 1998). In forestry, QOV approaches have been used to study management decisions under timber price volatility (Plantinga 1998), optimal thinning strategies in mixed species under climate change (Bredahl Jacobsen and Jellesmark Thorsen 2003), the decision to protect or harvest old growth forests in case of uncertainty on amenity (Conrad 1997) and the decision to convert a natural forest into Christmas tree production in case of uncertainty on groundwater pollution (Abildtrup and Strange 1999). To our knowledge, however, QOV has never been used in the analysis of timber species choice under climate change. Our paper applies the QOV approach to the question of species choice in the context of climate change. To do so, we use the example of the conversion of low-altitude Norway spruce stands to Douglas-fir.

As indicated in Farjon (1990), Norway spruce (Picea abies L. Karst) is commonplace in Alpine areas above 400-800 m of elevation, in Eastern and Northern Europe. The quality and versatility of Norway spruce wood has led to the establishment of many Norway spruce plantations, even at low altitude. Norway spruce is highly resistant to cold (it can withstand cold spells of up to $-40{ }^{\circ} \mathrm{C}$ ) and thus well-adapted to alpine and continental climates. Because of late bud burst, it is also not very sensitive to late frosts. On the other hand, Norway spruce is quite sensitive to water stress and droughts, both of which kill trees and favour insect attacks, for example, by bark beetles. As a result, the behaviour of Norway spruce under climate change has spurred considerable research (Seppälä et al. 2009).

A transition towards uneven-aged stands is one of the potential adaptation strategies for Norway spruce (Spiecker 2000). However, conversion towards tree species that are better adapted to future climatic conditions is regarded as a necessary option in many areas, notably at low altitude. Target species include, for example, European beech (Fagus orientalis L.) in the German Black Forest (Yousefpour et al. 2010) or Scots pine (Pinus sylvestris L.) in Northern Finland (Kellomäki et al. 2007). In the French Montagne Noire (43 $25^{\prime} 28^{\prime \prime} \mathrm{N}, 2^{\circ} 27^{\prime} 46^{\prime \prime} \mathrm{E}$ ), an increase in the mortality rate of Norway spruce is already observed (CRPF and Purpan 2007). The strategy of the French Forest Service is to replace 
Norway spruce by Douglas-fir in the most productive stations and to do nothing in the poorer ones.

In this paper, we explore the economics of replacing Norway spruce with Douglas-fir in the ecological context of the French Montagne Noire. Beyond the insights it provides for Norway spruce management in this particular context, this case study more generally illustrates how cost-benefit analysis under risk and QOV analysis can be used to provide insights on the opportunity and timing of species replacement under risk of climate change. We find that the land expectation value (LEV)maximizing strategy is sensitive to the a priori (subjective) probability attached to high mortality of Norway spruce under climate change. Given the large sunk costs associated with a transition to a new species (clearing and plantation), delay strategies are preferable both to transition and to status quo when the impact of climate change on Norway spruce mortality is sufficiently ambiguous. Interestingly, however, the range of subjective probabilities under which delaying action is LEV maximizing is not centred on $p=0.5$. We also estimate the economic value of getting earlier information about the impacts of climate change. Beyond the specifics of the case study, we thus argue that cost-benefit analysis and the QOV approach provide significant insights on how forest management should be adapted in the context of climate change.

\section{Materials and methods}

The method employed in the paper is economic calculation. Following Hallegatte et al. (2010), we proceed step by step to present our procedure. The first step is to identify the case study. The case study here is the transition from low-altitude Norway spruce to Douglas-fir, in French Montagne Noire. The second step is to describe the adaptation strategies considered in relation to the sources of uncertainty (Section 2.1), and the next subsection indicates the economic methods used to tackle the problem (Section 2.2).

\subsection{Definition of the adaptation strategies considered}

We consider a monoculture, even-aged Norway spruce stand that has just been clear-cut, and in which natural regeneration is present. We assume that in one century's time, Norway spruce will not be adapted to the stand anymore. In other words, regardless of the impacts of climate change on Norway spruce during the first rotation, it will be necessary to shift from Norway spruce to Douglas-fir in the second rotation. However, there is uncertainty surrounding the effects of climate change on Norway spruce during the first rotation.

The only source of uncertainty that we deal with is the climate change impact. The impacts of climate change on low-altitude Norway spruce plantations in the French Montagne Noire are uncertain for three cumulative reasons.
First, how the global climate will evolve over the next 70 years is uncertain - as it depends both on anthropogenic GHG emissions and on the climate reaction to these emissions. Second, how changes in the global climate will translate locally is very uncertain. Third, how Norway spruce plantations will react to changing conditions is unclear. Mapping these different uncertainties and coming up with a complete set of scenarios for Norway spruce evolution over time is thus a daunting task. Yet what really matters to inform a first-order economic analysis is not the overall trajectory of Norway spruce plantation, but some sense of the potential impacts of climate change on end-of-rotation revenues, and thus on timber production.

We assume two hypothetical scenarios regarding the impacts of climate change on Norway spruce. Either there is high mortality of Norway spruce over the next spruce rotation (70 years) or there is not. In the low-mortality case, Norway spruce production 70 years from now is assumed to be equal to current production, whereas under the high mortality scenario, we assume that final timber production drops by $80 \%$ relative to current levels.

The key to the subsequent analysis is the probability $p$ attached to the occurrence of the high-mortality scenario (respectively, $1-p$ for the low-mortality scenario). This probability might reflect the best judgment of scientists and experts on the possibility of the two scenarios occurring, it might reflect the forest manager's subjective beliefs about the occurrence of the two scenarios but not the forest manager's attitude towards risks, which is captured separately (Section 3.4). Section 3.1 of the results compares the next two strategies:

- Strategy 1: regenerating Norway spruce and shifting to Douglas-fir at the end of the rotation

- Strategy 2: planting Douglas-fir now, with natural regeneration of Douglas-fir in subsequent rotations.

However, because of research and development efforts (e.g. the DRYAD project in France, http://www.inra.fr/ dryade/le_projet), and because of increased experience with climate change impacts, it is likely that more information about the future mortality rate of Norway spruce will become available over time. Again, for the sake of simplicity, we assume that the uncertainty will be fully resolved in $n$ years (with $n=5$ or $n=10$ ). Section 3.2 compares the same two strategies (1 and 2) but now assumes that there is increasing information over time and that the forest owner may change for Douglas-fir after $n$ years, if she/he learns that there will be high mortality of Norway spruce during the first rotation.

In the case of increasing information, another strategy would be to wait until information is provided: the choice between regenerating Norway spruce and planting Douglasfir is postponed until more information about climate change impact becomes available (strategy 3). Section 3.3 compares this strategy to strategies 1 and 2 . 


\subsection{Economic method}

The first step in economic analysis is the evaluation of the costs and benefits for each project. We have the costs and benefits of Norway Spruce management and Douglas-fir management as presented in Tables 1 and 2 (for the lowmortality scenario).

The next step advocates calculating the net present value (NPV) of costs and benefits for one rotation. As indicated in Tables 1 and 2, we calculate this indicator for each strategy. The NPV is the present value of positive payments minus the present value of negative payments made at different points in time (Klemperer 1996).

The calculation is as follows:

$N P V=\sum_{i=0}^{n} \frac{B_{i}-C_{i}}{(1+r)^{i}}$

with $B$ the benefits, $C$ the costs, $r$ the discount rate and $n$ the rotation length.

The next step is to calculate the LEV associated with each project, which is the sum of all NPVs. In general, this indicator is calculated as follows:

$L E V=\sum_{i=0}^{\infty} \frac{B_{i}-C_{i}}{(1+r)^{i}}$

with $B$ the benefits, $C$ the costs and $r$ the discount rate. The forest owner's objective is to maximize the LEV.

QOV analyzes, in terms of LEV, whether the forest owner should wait before acting (i.e. choose strategy 3 ) or choose one of the two species now (strategy 1 or strategy 2). QOV is a way of measuring the benefit of flexibility in an uncertain context. QOV is defined as the difference between the

Table 1 Operations and benefits of Douglas-fir plantation and regeneration (Euros per hectare)

\begin{tabular}{lll}
\hline Operations (year) & $\begin{array}{l}\text { Benefits, } \\
\text { plantation }\end{array}$ & $\begin{array}{l}\text { Benefits, natural } \\
\text { regeneration }\end{array}$ \\
\hline Initial cost & Plantation (0): -2,132 & Clearing (3): -1,212 \\
Thinning (14) & -920 & $-1,170$ \\
Thinning (24) & 885 & 885 \\
Thinning (37) & 1,305 & 1,305 \\
Thinning (51) & 2,989 & 2,989 \\
Thinning (68) & 10,584 & 10,584 \\
Thinning (71) & 5,170 & 5,170 \\
Harvest (74) & 18,315 & 18,315 \\
Net present value & NPV(DF,plant)=452 & NPV(DF,rege) $=1,362$ \\
at 4 \% & & \\
\hline
\end{tabular}

Source: (Deltombe et al. 2008) adapted from Itinéraires Techniques de Travaux Sylvicoles, Le Pin Noir, Languedoc-Roussillon, Office National des Forêts, août 2002, 31 p
Table 2 Operations and benefits of Norway spruce regeneration as a function of the mortality scenario (Euros per hectare)

\begin{tabular}{lll}
\hline Operations (year) & $\begin{array}{l}\text { Benefits, low } \\
\text { mortality }^{\mathrm{a}}\end{array}$ & $\begin{array}{l}\text { Benefits, high } \\
\text { mortality }^{\mathrm{b}}\end{array}$ \\
\hline Clearing (0) & -597 & -597 \\
Thinning (20) & $-1,023$ & $-1,023$ \\
Thinning (40) & 1,242 & 621 \\
Thinning (50) & 1,518 & 506 \\
Thinning (60) & 2,139 & 535 \\
Harvest (70) & 19,417 & 3,883 \\
Net present value & $\mathrm{NPV}(\mathrm{NS})=859$ & $\mathrm{NPV}$ \\
at 4 \% & & \\
\hline
\end{tabular}

${ }^{\text {a }}$ Source: (Deltombe et al. 2008) adapted from Itinéraires Techniques de Travaux Sylvicoles, Le Sapin Pectiné, Languedoc-Roussillon, Office National des Forêts, août 2002, 31 p

${ }^{\mathrm{b}}$ Source: authors' estimates

LEV of the more flexible adaptation strategy (strategy 3 here) and the LEV of the next best alternative. A positive QOV means that it is more profitable to adopt the more flexible adaptation strategy than any other.

$Q O V=\operatorname{LEV}\left(\operatorname{Strat}_{3}\right)-\operatorname{Max}\left[\operatorname{LEV}\left(\operatorname{Strat}_{1}\right), \operatorname{LEV}\left(\operatorname{Strat}_{2}\right)\right]$

One major strength of QOV is that it focuses on flexibility. This method is thus well adapted for any choice in a context of increasing information, to analyze whether decisions should be made yet or postponed. However, it has weaknesses. Firstly, to be able to conduct this analysis, the probability of high mortality due to climate change and the delay before information is available have to be known. This is of course a simplification, but these data may be partly approached by the observation of climate state and forest response, and the knowledge of research agenda. Secondly, the QOV depends on the stream of costs and benefits of the delay strategy and the stream of costs and benefits of other strategies. Consequently, the choice to postpone (or not) a decision depends on assumptions on these costs and benefits. In the scientific debate on mitigation policies, the answer to the question "when to reduce?" did depend on assumptions on the irreversible environmental damage and on the sunk costs of abatement policies (Peterson 2006).

In relation to the analysis of LEV of the different strategies, one could also estimate the expected value of earlier information (EVEI). In other words, how much does the forest owner benefit when the information about the mortality scenario comes earlier? As in Nordhaus and Popp (1997), we define the EVEI as the increase in maximum achievable LEV when the information comes earlier. The EVEI is the difference between the maximum achievable LEV if information becomes available in 5 years and 
maximum achievable LEV if information becomes available in 10 years:

$$
\begin{aligned}
E V E I= & \operatorname{Max}\left[L E V_{5}\left(\operatorname{Strat}_{1}\right), \operatorname{LEV}_{5}\left(\operatorname{Strat}_{2}\right), L E V_{5}\left(\operatorname{Strat}_{3}\right)\right] \\
& -\operatorname{Max}\left[L E V_{10}\left(\operatorname{Strat}_{1}\right), L E V_{10}\left(\operatorname{Strat}_{2}\right), L E V_{10}\left(\operatorname{Strat}_{3}\right)\right]
\end{aligned}
$$

Earlier information is thus valuable either because it gives more benefits to a given strategy or because it changes the LEV-maximizing strategy.

The last step consists in the evaluation of the strength of the results. In this paper, the strength is evaluated through sensitivity analysis, in particular, of parameter $p$ representing the hypothetical impact of climate change on Norway spruce.

\section{Results}

3.1 Immediate and irreversible choice between Norway spruce and Douglas-fir, with no ability to shift course

In this section, we consider strategies 1 and 2. We assume that even in the high-mortality scenario, forest managers would not deviate from strategy 1 , and thus stick to the Norway spruce plantation all the way to final harvest (i.e. all the way to year 70). It can be interpreted as a case in which no information on spruce mortality is provided to forest managers before final harvest. It can also be interpreted as a situation in which, for institutional, legal or financial reasons, forest managers cannot shift course even if they get new information. The decision tree is given in Fig. 1.

We first analyze the economics of strategy 2 , then the economics of strategy 1, and finally the choice between strategy 1 and strategy 2 .

\subsubsection{Economic analysis of strategy 2}

We assume that Douglas-fir is suitable to both current and future climate conditions, and also, both the yields and the financial payoffs of strategy 2 are independent of the spruce mortality scenario (see Table 1). The LEV of strategy 2 (denoted LEV(DF)) is then

$$
\begin{aligned}
\operatorname{LEV}(D F) & =N P V(D F, \text { plant })+\frac{N P V(D F, \text { rege })}{(1+r)^{74}} \times \frac{(1+r)^{74}}{(1+r)^{74}-1} \\
& =452+\frac{1,362}{(1+r)^{74}} \times \frac{(1+r)^{74}}{(1+r)^{74}-1}=€ 531 / h a
\end{aligned}
$$

\subsubsection{Economic analysis of strategy 1}

Norway spruce production depends on the scenario. Net benefits associated with Norway spruce under the

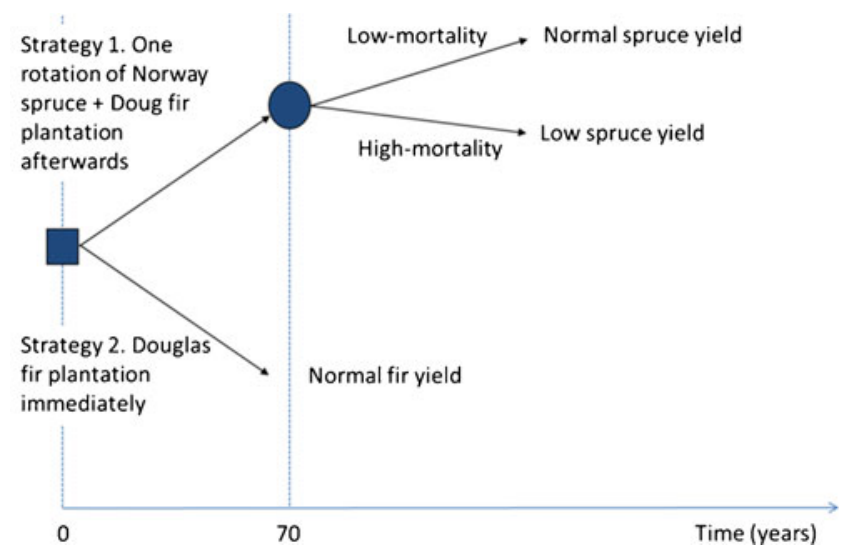

Fig. 1 Decision tree. Immediate and irreversible choice between Norway spruce and Douglas-fir, with no ability to shift course

low- and high-mortality scenarios are detailed in Table 2.

In the low-mortality scenario, the LEV of strategy 1 ("Norway spruce + Douglas-fir"), denoted LEV(NS), would be

$L E V(N S)=N P V(N S)+\frac{L E V(D F)}{(1+r)^{70}}=€ 893 / h a$,

with NPV(NS) the NPV of Norway spruce regeneration in the low-mortality scenario.

In the high-mortality scenario, the LEV of strategy 1 , denoted $\mathrm{LEV}_{\mathrm{CC}}(\mathrm{NS})$, would be

$L E V_{C C}(N S)=N P V_{C C}(N S)+\frac{L E V(D F)}{(1+r)^{70}}=-€ 529 / h a$,

with $\mathrm{NPV}_{\mathrm{CC}}(\mathrm{NS})$ the NPV of Norway spruce regeneration in the high-mortality scenario.

In the low-mortality scenario, strategy 1 is thus preferable to strategy 2 . In the high-mortality scenario, on the other hand, the ranking is the opposite.

The LEV attached to strategy 1 is

$$
\begin{aligned}
L E V\left(\text { Strat }_{1}\right) & =p L E V_{C C}(N S)+(1-p) L E V(N S) \\
& =-529 p+892(1-p)=892-1,421 p .
\end{aligned}
$$

\subsubsection{Choice between strategy 1 and strategy 2}

The LEV attached to strategy 1 is positive if $p$ is lower than 0.63 . It exceeds the LEV of strategy 2 if $p$ is lower than 0.25 . In other words, forest managers should choose strategy 1 only if high spruce mortality is deemed unlikely or very unlikely (as per the IPCC likelihood scale, Mastrandrea et al. 2010). The threshold probability is very sensitive to discount rate. For discount rates of $3 \%$ or lower, strategy 1 never dominates strategy 2. This is because the lower the discount rate, the lower the initial investment costs associated with strategy 2 
(clearing and plantation). In the remainder of the paper, we assume a $4 \%$ discount rate to keep the choice between strategies dependent on $p$.

\subsection{Immediate and irreversible choice between Norway} spruce and Douglas-fir, with ability to shift course

We now assume that the forest manager knows whether we are in high- or in a low-mortality scenario before the year 20 , in year $n=5$ or 10 . In addition, we assume that if the forest manager has selected strategy 1 , and if it turns out that we are in a high-mortality scenario, she/he can shift course by cutting the spruce and planting Douglas-fir immediately. In such a case, however, she/he would incur a $€ 100$ increase in plantation costs due to higher clearing costs before plantation. The decision tree of the forest owner is described in Fig. 2.

To solve this problem, one must first determine the LEVmaximizing course of action after information is revealed. If spruce mortality happens to be low (top right decision node in Fig. 2), it follows from our previous assumptions that continuing with the spruce plantation is preferable to shifting course. If, on the other hand, spruce mortality happens to be high, it is not entirely obvious that shifting course is preferable because whether $n=5$ or 10 , some of the costs associated with spruce (namely, the initial €597/ha) have already been incurred and thus should not be factored into the analysis. From year $n$ onward, the stream of net benefits associated with continuing with the spruce plantation to the end is given in Table 3. To the NPV of pursuing the spruce plantation until the end, one must add the LEV of shifting to Douglas-fir permanently, discounted by $70-n$ years. Overall, continuing the spruce rotation till the end and shifting to Douglas-fir afterwards in the high-mortality case would yield a LEV of $€ 82 /$ ha if $n=5$, and $€ 100 /$ ha if $n=10$. In both

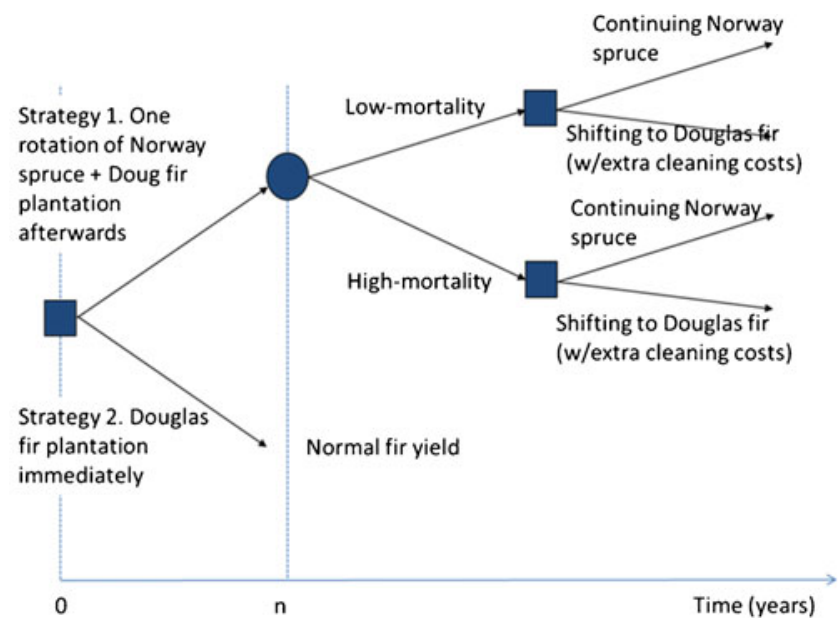

Fig. 2 Decision tree. Immediate and irreversible choice between Norway spruce and Douglas-fir, with increasing information and ability to shift course before the end

cases, this is lower than the LEV associated with shifting to Douglas-fir immediately (LEV(DF) $=€ 531 /$ ha).

So shifting to Douglas-fir is preferable in the highmortality scenario, even accounting for the $€ 100 /$ ha extra clearing cost. The decision tree presented in Fig. 2 is thus simplified. Indeed, the axis representing strategy 2 stays identical but the axis for strategy 1 simplifies. In case of low mortality, the only issue becomes "continuing with Norway spruce", and in case of high mortality, it becomes "shifting to Douglas-fir (with the extra clearing cost)".

It is important to note that the above result is sensitive to the date at which information is available. In fact, if the information becomes available after the year-20 thinning, then it would no longer be cost-effective to shift to Douglasfir even if the high-mortality scenario was realized. This is because the large costs of the thinning at year 20 would have been incurred, thus increasing the cost-effectiveness of staying the course.

Coming back to the $n=5$ or 10 case, the LEV associated with strategy 1 is

$$
\begin{aligned}
L E V(\text { Strat ... 1) }= & p\left(-597+\frac{L E V(D F)-100}{(1+r)^{n}}\right)+(1-p) \\
& \times\left(N P V(N S)+\frac{L E V(D F)}{(1+r)^{70}}\right) .
\end{aligned}
$$

For $n=5$, the threshold value of $p$ is 0.319 . If $p<31.9 \%$, it is better to regenerate Norway spruce, and if $p>31.9 \%$, it is better to plant Douglas-fir. For $n=10$, the threshold probability is basically identical (0.302). When additional information is provided and forest managers are able to shift course, Norway spruce regeneration strategies become LEV maximizing if the perceived risk of high mortality is smaller than 0.32 (for $0<p<0.32$ ). This range of probabilities is higher than in the case where no information is provided (see Section 3.1.3: $0<p<0.25$ in the case with no additional information).

More important in practice is the fact that there are benefits attached to a delay strategy in which forest owners postpone their decision (with limited costs) until new data

Table 3 Operations and benefits of Norway spruce regeneration from year $n$ onward under the high-mortality scenario (Euros per hectare)

Source: authors' estimates

\begin{tabular}{ll}
\hline Operations (year) & Benefits \\
\hline Thinning $(20-n)$ & $-1,023$ \\
Thinning $(40-n)$ & 621 \\
Thinning $(50-n)$ & 506 \\
Thinning $(60-n)$ & 535 \\
Harvest $(70-n)$ & 3,883 \\
NPV at $4 \%(n=5)$ & 41 \\
NPV at $4 \%(n=10)$ & 50 \\
\hline
\end{tabular}


becomes available. The next section examines this extended decision problem.

\subsection{Sequential decision making with risk neutrality}

We consider a third strategy in which the choice between regenerating Norway spruce and planting Douglas-fir is postponed until the information about whether the mortality rate of spruce is "high" or "low" is provided. The decision problem is now represented in Fig. 3.

During this period, we assume that no investment is made on the stand. Norway spruce naturally regenerates and highdensity vegetation establishes. As a result, it is more expensive to clear the stand afterwards, both for continuing with Norway spruce and for planting Douglas-fir. Precisely, we assume that the clearance costs associated with Norway spruce regeneration increase to $€ 800 /$ ha after a waiting period of 5 years and to $€ 900 /$ ha after a waiting period of 10 years. Similarly, we assume that the cost of Douglas-fir plantation increases because of clearing and grinding: there is a $€ 100 /$ ha increase relative to strategy 1 , for the two waiting periods.

In this new decision problem, the LEV associated with immediate Norway spruce regeneration (strategy 1) is the same as in the previous section. The LEV associated with immediate plantation of Douglas-fir is also the same as before. So, we only need to compute the LEV associated with strategy 3.

\subsubsection{Economic analysis of strategy 3}

Following the same steps as above, we first need to find the LEV-maximizing strategy at year $n$ when information has become available (decision nodes on the bottom right part of Fig. 3), before computing the LEV associated with the choice of strategy 3 now. The LEV at year $n$ associated with planting Douglas-fir is LEV(DF) $-100=€ 431 / \mathrm{ha}$. This value

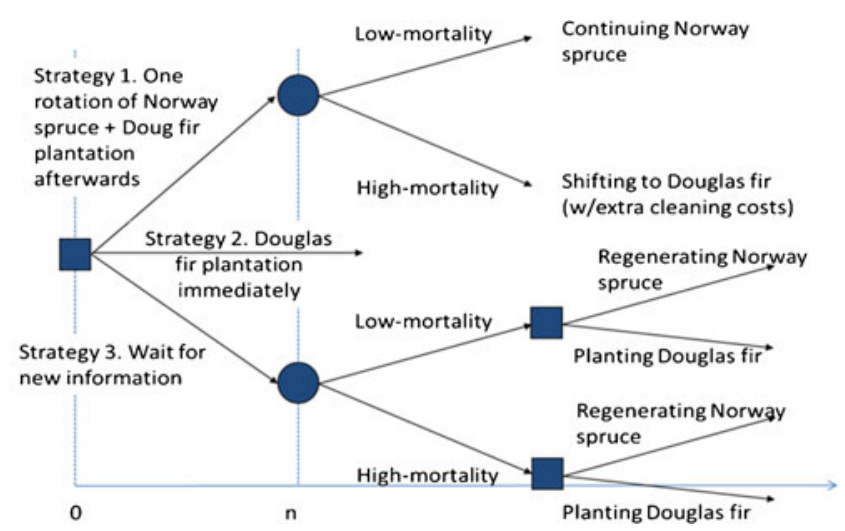

Fig. 3 Decision tree. Choice between Norway spruce regeneration, Douglas-fir conversion or delay until new information becomes available is the same whether we are in a high- or low-mortality scenario.

If the forest owner keeps the regeneration of Norway spruce, after the waiting period, the stand will be harvested at the same date as before: 70 years after natural regeneration or $70-n$ years after the waiting period. We assume that there is a small decrease in production because of the waiting period: production is $5 \%$ lower than in strategy 1 , for a waiting period of 5 years, and $10 \%$ lower for a waiting period of 10 years (all costs and benefits are detailed in Table 4). The LEV at year $n$ associated with continuing with Norway spruce depends both on $n$ (because clearing costs, benefits and the remaining time before harvest vary) and on the mortality scenario that is realized. When $n=5(n=10)$, the LEV equals $€ 854 / \mathrm{ha}$ (€971/ha) in the low-mortality scenario and $-€ 748 /$ ha $(-€ 873 /$ ha) in the high-mortality scenario.

We call LEV $(\mathrm{NS}, n)$ the LEV associated with Norway spruce regeneration in the low-mortality case (i.e. $\operatorname{LEV}(\mathrm{NS}, 5)=854$ and $\operatorname{LEV}(\mathrm{NS}, 10)=971)$ and $\mathrm{NPV}(\mathrm{NS}, n)$ the NPV in the same case. Since the Norway spruce will be harvested in $70-n$ years, $\mathrm{LEV}(\mathrm{NS}, n)$ equals

$L E V(N S, n)=N P V(N S, n)+\frac{L E V(D F)}{(1+r)^{70-\mathrm{n}}}$.

The best choice for the forest owner is thus to regenerate the Norway spruce if the low-mortality scenario is realized, and to plant Douglas-fir otherwise. The decision tree presented in Fig. 3 thus simplifies. Indeed, the axis for strategy 1 and 2 does not change, but the axis for strategy 3 is modified. In the event of low mortality, the only issue is "regenerating Norway spruce (with extra clearance costs and smaller benefits)", and in case of high mortality, the only issue becomes "planting Douglas-fir (with extra clearing costs)".

Strategy 3 differs from strategy 1 because clearance is postponed until the information is provided, in strategy 3 , and consequently, there are higher clearance costs at year $n$ and smaller benefits.

The LEV of strategy 3 thus becomes

$L E V\left(\right.$ Strat $\left._{3}\right)=\frac{1}{(1+r)^{n}}(p(L E V(D F)-100)+(1-p) L E V(N S, n))$.

The choice between "Norway spruce regeneration", "Douglas-fir plantation" and "Delay" depends on the expected probability of the "high-mortality" scenario, and on the expected time required for perfect information to become available. When the probability of the "high mortality" scenario is very low, it is cost-effective to go ahead and regenerate the spruce immediately (strategy 1). Similarly, for a high probability of the "high-mortality" scenario, it becomes cost- 
Table 4 Operations and benefits of Norway spruce regeneration from year $n$, with a waiting period of $n$ years before clearance (Euros per hecare)

\begin{tabular}{|c|c|c|c|c|}
\hline \multirow[t]{2}{*}{ Operations (year) } & \multicolumn{2}{|c|}{ Year 5, with a waiting period of 5 years } & \multicolumn{2}{|c|}{ Year 10 , with a waiting period of 10 years } \\
\hline & Benefits, low mortality & Benefits, high mortality & Benefits, low mortality & Benefits, high mortality \\
\hline Clearing (0) & -800 & -800 & -900 & -900 \\
\hline Thinning (10) & & & $-1,023$ & $-1,023$ \\
\hline Thinning (15) & $-1,023$ & $-1,023$ & & \\
\hline Thinning (30) & & & 1,117 & 559 \\
\hline Thinning (35) & 1,180 & 590 & & \\
\hline Thinning (40) & & & 1,366 & 455 \\
\hline Thinning (45) & 1,442 & 481 & & \\
\hline Thinning (50) & & & 1,925 & 481 \\
\hline Thinning (55) & 2,032 & 508 & & \\
\hline Harvest (60) & & & 17,475 & 3,495 \\
\hline Harvest (65) & 18,446 & 3,689 & & \\
\hline Net present value at $4 \%$ & $\mathrm{NPV}(\mathrm{NS}, 5)=854$ & $\mathrm{NPV}(\mathrm{NS}, 5)=-748$ & $\mathrm{NPV}(\mathrm{NS}, 10)=971$ & $\mathrm{NPV}(\mathrm{NS}, 10)=-873$ \\
\hline
\end{tabular}

Source: authors' estimates

effective to shift to Douglas-fir immediately (strategy 2). However, for intermediate values of the probability (for $n=5,0.208<p<0.538$; for $n=10,0.254<p<0.399$ ), the "Delay" option (strategy 3) should be preferred, as it leaves all options open in a context of high uncertainty about the mortality rate of the spruce. So, the analysis in terms of QOV shows when it is better to choose one of the two species (Norway spruce or Douglas fir) and when it is better to wait before choosing (strategy 3 ).

It is interesting to note that the distribution in Fig. 4 is not symmetric. It is only with very low probability of "high mortality" that one should go ahead and regenerate Norway spruce. It becomes cost-effective to shift to Douglas-fir immediately starting at a $53.8 \%$ probability of "high mortality". These threshold probabilities depend on the stream of costs and benefits of the alternatives (strategy 1, strategy 2 and strategy 3). The LEV of strategy 1 decreases strongly with an increase in the probability of high mortality because the Norway spruce regeneration is destroyed in case of high mortality. The LEV of strategy 3 decreases slowly with an increase in the probability of high mortality. This is due to the fact that (1) loss in case of high mortality is reduced by the postponement of the clearance cost and (2) the benefits are smaller in case of low mortality because the clearance is delayed.

\subsubsection{Quasi-option value analysis}

QOV is calculated as the difference between the LEV of the delay strategy and the LEV of the next best alternative (see Eq. 3).

Figure 5 presents the QOV function of the probability of "high-mortality" scenario when information is provided at $n=5$ or $n=10$. It shows that it is always less profitable to delay the decision between Norway spruce and Douglas-fir when information comes 10 years later. In fact, increasing the delay decreases the LEV attached to strategy 3 for two reasons. First, a longer delay implies higher clearance costs. Second, a longer delay reduces future production and benefits. The LEV attached to strategy 1 also diminishes with the length of the delay, as the shift towards Douglas-fir, if it becomes necessary, can occur earlier with a lower $n$ (discount effect). Yet an increase in $n$ has a higher impact on the LEV of strategy 3 than on the LEV of strategy 1 (the LEV of strategy 2 is independent of $n$ ).

We also compute the EVEI attached with the 5-year gain from information becoming available in year 10 compared to information becoming available in year 5 (see Eq. 4). (The method can of course be applied to any other variation in the time at which information becomes available.)

Figure 5 plots the EVEI as a function of $p$. The EVEI is not constant with $p$. For a high level of $p(p \geq 53.8 \%)$, the EVEI is zero (no benefit in getting information earlier) because the best strategy in this case is strategy 2 , the payoff of which is independent of $n$. For low values of $p, p \leq$ $20.8 \%$, the EVEI is positive as the payoff of the best strategy (strategy 1 ) is $n$-dependent, and for medium values of $p, 25.4 \% \leq p \leq 39.9 \%$, the positive value of EVEI is also due to the $n$-dependence of the payoff of strategy 3 . In between, there is a positive value to earlier information because it changes the LEV maximizing strategy. The best strategy with earlier information is strategy 3 instead of strategy 1 for $20.8 \% \leq p \leq 25.4 \%$, and strategy 3 instead of strategy 2 for $39.9 \% \leq p \leq 53.8 \%$.

So, EVEI is low for very low or very high probabilities of high mortality. In between, EVEI is between 10 and $€ 50 /$ ha: it increases the LEV by $2 \%$ to $9 \%$. 
Fig. 4 Land expected value of the "Delay" scenario (for $n=5$ ) relative to the best scenario between spruce regeneration and planting Douglas-fir (Euros per hectare)

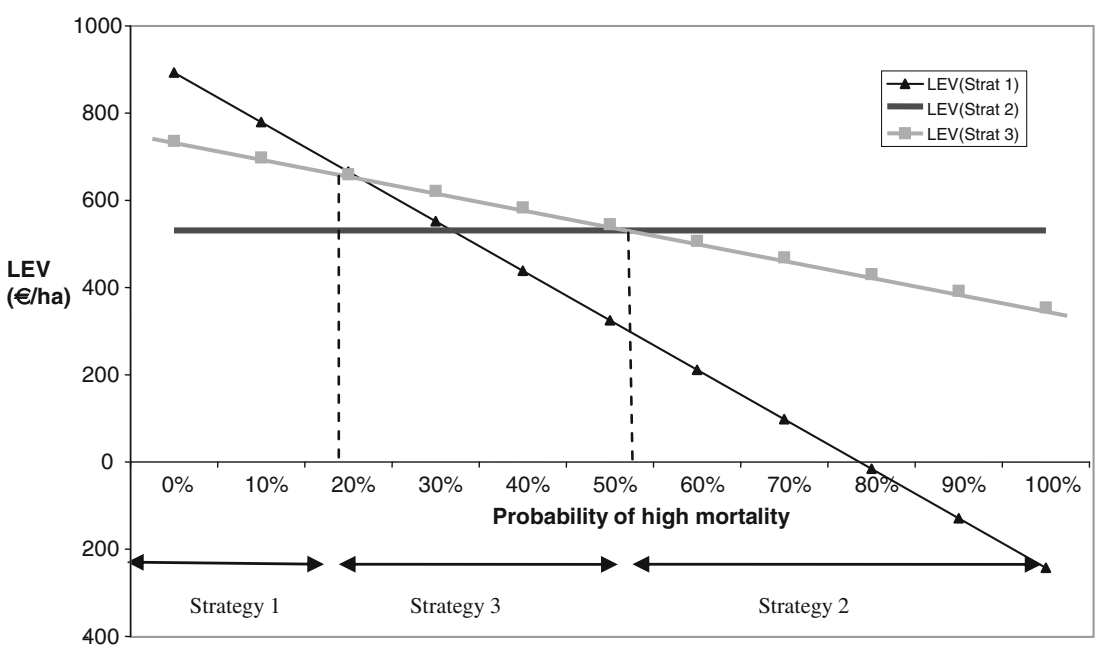

\subsection{Sequential decision making with risk aversion}

In this section, we introduce risk aversion to test the robustness of our results to this assumption. We use the constant relative risk aversion (CRRA) utility function, i.e. $U(x)=x^{\beta}$ with $U^{\prime}()>$.0 and $U^{\prime \prime}()<$.0 , and $\beta$ the relative risk aversion coefficient. The use of a CRRA specification is commonly found in the literature concerning risk economics (Harrison and Rutström 2008). $\beta=1$ represents risk neutrality, $\beta>1$ corresponds to risk-seeking preferences and $\beta<1$ to risk aversion, so that we assume $\beta<1$. Moreover, in some cases, we have negative $x$. Taking negative $x$ into account leads us to consider that $\beta$ is an integer. As there is no estimation of the $\beta$ coefficient for private forest owners in the literature, we choose arbitrary $\beta=-1$ (see Section 4.2 for a sensitivity analysis on this parameter).

In France, forest revenues typically represent a low share of private forest owners' total holdings and total income because forest management is often a secondary activity. Thus, we adopt a reasoning at the margin in which the owner maximizes the marginal utility associated with each additional unit of forest revenue. We circumvent the difficulties associated with measuring the utility benefits of the stream of forestry

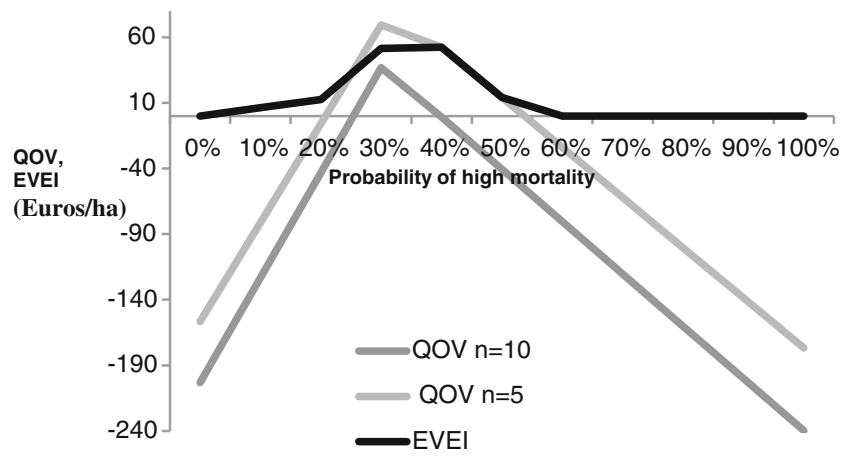

Fig. 5 Quasi-option value and expected value of earlier information as a function of the probability of high mortality (Euros per hectare) revenues by considering only the aggregated LEV and viewing it as an income stream. This income stream being marginal compared to the total income of the forest owners, we are in the case of marginal projects (Drèze and Stern 1987), which are then analyzed in terms of marginal utility.

Now, to evaluate strategy 1 , we consider that the expected marginal utility of strategy 1 is

$$
\begin{aligned}
E U^{\prime}(\text { Strat } 1) & =p U^{\prime}(x)+(1-p) U^{\prime}(x) \\
& =p\left(\beta x^{(\beta-1)}\right)+(1-p)\left(\beta x^{(\beta-1)}\right)
\end{aligned}
$$

with $U^{\prime}($.$) the marginal utility, \beta$ the relative risk aversion coefficient and $x$ the income of the forest owner which depends on the probability of the high-mortality scenario, $p$.

If the probability is high, the income of the owner is $x=-597+\frac{L E V(D F)-100}{(1+r)^{n}}$, which corresponds to the LEV of the forest if the owner has to shift to Douglas-fir after $n$ years.

If the probability is not high, then the income of the owner is $x=N P V(N S)+\frac{L E V(D F)}{(1+r)^{70}}$, which represents the LEV of the forest if the owner keeps Norway spruce.

The same reasoning applies for the two other strategies.

We show that the results obtained with risk neutrality stay valid for $n=5$. Indeed, the introduction of the risk aversion does not modify the trends. For low probability of "high mortality", the forest owner's marginal utility is higher with strategy 1, for high probability of "high mortality", strategy 2 must be prioritized, while for an intermediate value of the probability, strategy 3 seems to be relevant. The only modification bears on the interval of probabilities in which each strategy dominates. Indeed, with risk aversion, strategy 1 dominates only for a very low value of the probability $(p<0.0617)$, strategy 3 dominates for a lower range of probabilities $(0.0617<p<0.278)$ and strategy 2 for a higher range of probabilities $(p>0.278)$ than without risk aversion. 
Considering $n=10$ changes the results obtained with risk neutrality. Indeed, with $n=10$ and risk aversion, strategy 3 never dominates the two other strategies. For probabilities of "high mortality" inferior to $24.29 \%$, strategy 1 dominates, and for $p>24.29 \%$, strategy 2 dominates. Then, the additional unit of income provided by strategy 3 always procures a lower utility.

To sum up, it appears that the probability for which the Delay strategy dominates is reduced with risk aversion compared to risk neutrality, irrespective of $n$. Moreover, considering $n=10$ leads to the extreme result of never choosing strategy 3 , irrespective of $p$. This result comes from the fact that strategy 3 is seen, by the risk averse forest owner, as a riskier option than strategies 1 and 2. Moreover, it appears that the riskiness of strategy 3 increases as $n$ rises, explaining why strategy 3 is abandoned by the owner.

In addition, under risk aversion, strategy 2 is chosen for the wider range of probabilities. This result is due to the certainty associated with strategy 2 . Indeed, with strategy 2 , the forest owner is certain to obtain $€ 531 /$ ha irrespective of $n$ and $p$. This reaction is directly explained by the definition of risk aversion: reluctance of a person to accept a bargain with an uncertain payoff rather than another bargain with a more certain, but possibly lower, expected payoff.

We look also at the QOV which is now the difference between the marginal utility of strategy 3 and the marginal utility of the next best alternative. We show that, as in the case of risk neutrality, it is less often profitable to delay the decision between Norway spruce and Douglas-fir when information comes 10 years later.

\section{Discussion}

\subsection{Discount rate}

The results obtained here do depend on the discount rate. If financial markets were perfect, the discount rate should be equal to the available rate in financial markets. Financial markets being imperfect, there is not one discount rate. In France, the guidelines produced by the French Plan (Commissariat Général au Plan) are to use a discount rate of between $2 \%$ and $4 \%$ for a public project, depending on the length of the project. In particular, the discount rate for public projects should be equal to $2.85 \%$ for a 70 -year project (Lebègue et al. 2005). In the case of private projects, the discount rate used depends on the other investment opportunities for the forest owner, on the risk aversion and on the time preferences. Since the discount rate depends on individual characteristics, one way to estimate the individual discount rate when the forest owner is not able to give it is to calculate the rate from the market land value of the forest, and the owner's management practices (Peyron et al. 1998).
The discount rate we use, $4 \%$, is rather high by comparison to the public discount rate in France. A decrease in the discount rate used would imply that the delay strategy is less often the most profitable strategy. A decrease in the discount rate makes the future incomes of Douglas-fir higher, and thus the strategy to switch to Douglas-fir is more often the best strategy. Consequently, the discount rate is one major component of the economic analysis in terms of QOV, as it is one major component of usual cost-benefit analysis of management choices.

The scope of our paper is to show how the methodology of QOV helps to analyze the question of species choice in the context of climate change, through a very simplified case. In a detailed work on species choice, it would be necessary either to determine the discount rate of the forest owner or to analyze the sensitivity of the results to the discount rate.

\subsection{Risk aversion}

We show that as $\beta$ decreases (increased risk aversion), the effects described in Section 3.4 are amplified. Indeed, for $n=$ 5 , strategy 1 dominates for values of the probability lower than in the case where $\beta=-1$, next comes strategy 3 but also for a lower range of probabilities than in the case where $\beta=-1$, and finally, strategy 2 offers the best option but for a wider range of probabilities than in the case where $\beta=-1$. For $n=10$, strategy 3 never dominates the two others, and the range of the probabilities for which strategy 1 dominates is reduced compared to the situation where $\beta=-1$. To sum up, irrespective of $n$, as risk aversion rises, the range of probabilities for which strategy 2 dominates increases.

We also look at what happens in case of risk-seeking. To do so, we consider the relative risk aversion coefficient to be superior to 1 . We show that as the coefficient increases (increased risk-seeking) and irrespective of $n$, strategy 3 never dominates the two others. The risk-seeking owner arbitrates between strategy 1 and 2 as a function of the value of the probability of high mortality. We observe that strategy 1 is chosen for a wider range of probabilities than strategy 2 . This behaviour is due to the fact that strategy 1 represents the riskier strategy among the three analyzed in the paper.

We can conclude, in accordance with Yousefpour et al. (2012) that forest owner's attitude towards risk plays a significant role in the analysis of adaptation strategies to face climate change. This sensitivity analysis also underlines the need for a precise estimation of forest owner's risk aversion coefficient for future research.

\subsection{Is Douglas-fir plantation a perfect adaptation strategy?}

Douglas-fir is more tolerant than Norway spruce to water stress and droughts, but it might not be tolerant enough to be 
perfectly adapted to climate change, for two main reasons. First, Douglas-fir productivity may differ under the highand low-spruce mortality scenario. Second, climate change is a continuous process, and Douglas-fir itself might no longer be suited to the long-term climate in the second or third rotation. If Douglas fir is not perfectly adapted to climate change, the LEV of strategy 2 would fall. As a consequence, the choice between strategy 1 , strategy 2 and strategy 3 would be less often in favour of strategy 2. In other words, as the benefits of Douglas-fir are smaller, the high sunk costs would reduce its profitability.

\subsection{Are waiting periods of 5 and 10 years relevant?}

We assume here that forest owners know in 5 or 10 years if Norway spruce will be well adapted to the future climate. Such a delay may seem rather optimistic, but we are aiming to illustrate the methodology. The same methodology would apply for a longer period. In the case studied here, we can assume that a longer delay before information would make the delay strategy never cost-effective because of an increase in the clearance costs. However, in other cases (other contexts or other species), the waiting strategy might be profitable even if the delay is much longer. In particular, the increase in clearance costs during the waiting period is related to the growth rate, which depends on the species and on the stand. However, the aim of our paper is to show that the analysis of species choice under the climate change condition should take into account the sequential timing of information through a sequential decision making analysis. Our simple case study shows that flexible management strategy might be better than immediate decision between species, depending on economic and ecological conditions. We argue that further research on management practices for forest adaptation to climate change should include sequential decision making and arrival of information into the analysis, through a QOV approach.

One of the delay strategies could be to replace in-stand species with transition species which grow rapidly and which are adapted to a wide range of climatic conditions (Piermont 2007). The economic analysis should then be conducted as before, land expected value of the delay strategy then being the sum of the NPV of the transition species plus the NPV of the future species over infinite rotations. Of course, such a delay strategy might be very costly because of the capital cost of plantation of the transition species, and then because of the capital cost of clearing before the plantation of another species. One of the transition species is the black locus tree, for which the capital cost of clearing might be very high. Our analysis shows that the delay strategy is preferred if it is not too costly, so the delay strategy with transition species might be not the best choice.

\section{Conclusion}

We consider the case of a monoculture stand which has just been harvested. The forest owner then has three possible strategies: she/he keeps the in-stand species (here Norway spruce) and thus clears the stand to help natural regeneration, or she/he changes for another species (here Douglasfir), or she/he does nothing and waits to have more information before choosing between these two species (delay strategy). It is assumed that without climate change, the instand species is the more profitable because the plantation of Douglas-fir implies high costs.

It is shown that the best timing of the species choice depends on the subjective probability of high mortality of Norway spruce. If the ambiguity is low (this probability is rather high or rather low), it is more profitable to choose now. Of course, the choice depends on the probability: if the forest owner expects a high mortality of Norway spruce, it is better to replace it by Douglas-fir. In practice, scientific knowledge on climate change effects will not provide exact estimates of the probability of high mortality, but will provide information that may help forest owners to estimate subjective probabilities. In other words, scientific knowledge will help to decide the range of probabilities that has to be considered. This has material implications for the analysis, as experts, even if they cannot provide a precise probability, may well be able to say whether that probability is higher or lower than a half, which is the threshold value of probability above which it is profitable to switch to Douglas-fir. If the forest owner thinks that mortality of Norway spruce will be usual, it is better to keep Norway spruce. When the ambiguity is high, the delay strategy is the more cost effective one since the increase in clearing costs of Norway spruce on one side or the cost due to a delay in Douglas-fir plantation on the other side do not rise too high because of the delay. It is shown that these results stay valid in case of forest owner's risk aversion.

We also analyze the value of information. It is shown here that information has a value because it might change the choice of forest owners, or because it changes the LEV for a given strategy. Research work on forest adaptation to climate change that provides knowledge earlier on what could be the mortality of different species induces an economic benefit, which is estimated in our example to belong to the interval $€[6-52] / h a$.

Acknowledgments The authors acknowledge the help of Eric Lacombe and four AgroParisTech students, Martin Deltombe, JeanBaptiste Reboul, Nicolas Toquard and Emmanuel Bonaimé, for their contribution to the case study. We also thank Bo Jellesmark Thorsen and participants in the international conference "Tackling climate change: the contribution of forest scientific knowledge" held in Tours in May 2012 for helpful suggestions. Finally, we are grateful to two anonymous referees for their comments. 


\section{References}

Abildtrup J, Strange N (1999) The option value of non-contaminated forest watersheds. Forest Policy Econ 1:115-125

Arrow KJ, Fisher AC (1974) Environmental preservation, uncertainty, and irreversibility. Q J Econ 88:312-319

Becker M, Nieminen TM, Geremia F (1994) Short-term variations and long-term changes in oak productivity in north-eastern France: the role of climate and atmospheric CO2. Ann For Sci 51:477-492

Bolte A, Czajkowski T, Kompa T (2007) The north-eastern distribution area of European beech: a review. Forestry 80:413-429

Bredahl Jacobsen J, Jellesmark Thorsen B (2003) A Danish example of optimal thinning strategies in mixed-species forest under changing growth conditions caused by climate change. Forest Ecol Manag 180:375-388

Bricenõ-Elizondo E, Garcia-Gonzalo J, Peltola H, Matala J, Kellomäki S (2006) Sensitivity of growth of Scots pine, Norway Spruce and Silver Birch to climate change and forest management in boreal conditions. Forest Ecol Manag 232:152-167

Carina E, Keskitalo H (2011) How can forest management adapt to climate change? Possibilities in different forestry systems. Forests 2:415-430

Conrad JM (1997) On the option value of old-growth forest. Ecol Econ 22:97-102

CRPF, ONF, Purpan (2007) Dépérissement des reboisements résineux de l'Aveyron et du Tarn. Etat des lieux. Miméo 5p

Deltombe M, Reboul JB, Toquard N, Bonaimé E (2008) Analyse économique de choix sylvicoles adaptés aux changements climatiques, rapport de TP d'économie, FIF-AgroParisTech, $38 \mathrm{p}$

Drèze J, Stern NH (1987) The theory of cost-benefit analysis. Chapter 14 in Handbook of Public Economics, vol 2., pp 909-989

Farjon A (1990) Pinaceae, drawings and description of the genera. Koeltz Scientific Books, Germany, $330 \mathrm{p}$

Guariguata MR, Cornelius JP, Locatelli B, Forner C, Sánchez-Azofeifa GA (2008) Mitigation needs adaptation: tropical forestry and climate change. Mitig Adapt Strat Global Change 13:793-808

Ha-Duong M (1998) Quasi option value and climate policy choices. Energ Econ 20:599-620

Hallegatte S, Lecocq F, de Perthuis C (2010) Économie de l'adaptation au changement climatique. Rapport du Conseil Economique pour le Développement Durable (CEDD)

Hanewinkel M, Hummel S, Cullmann DA (2010) Modelling and economic evaluation of forest biome shifts under climate change in Southwest Germany. Forest Ecol Manag 259:710-719

Hanewinkel M, Cullman DA, Schelhaas MJ, Nabuurs GJ, Zimmermann NE (2012) Climate change may cause severe loss in the economic value of European forest land. Nature Clim Change. doi:10.1038/nclimate1687

Harrison G, Rutström E (2008) Risk aversion in the laboratory. Res Exp Econ 12:41-196

Henry C (1974) Investment decisions under uncertainty: the irreversibility effect. Am Econ Rev 64:1006-1012

IPCC (2007) Climate change 2007, synthesis report. In: Pachauri RK, Reisinger A (eds) Contribution of working groups I, II and III to the fourth assessment report of the Intergovernmental Panel of Climate Change, Core Writing Team. IPCC, Geneva, Switzerland, $104 \mathrm{p}$

Kellomäki S, Peltola H, Nuutinen T, Korhonen KT, Strandman H (2007) Sensitivity of managed boreal forests in Finland to climate change, with implications for adaptive management. Philos Trans R Soc Series B Biol Sci 363:2341-2351

Klemperer WD (1996) Forest resource economics and finance, McGraw-Hill Series in Forest Resources. McGraw-Hill, New York, 551p

Lebègue D, Baumstark L, Hirztman P (2005) Révision du taux d'actualisation des investissements publics, Commissariat Général au Plan. France, $112 \mathrm{p}$

Lönnstedt L, Svensson J (2000) Non-industrial private forest owner's risk preferences. Scand J Forest Res 15:651-660

Mastrandrea MD, Field CB, Stocker TF, Edenhofer O, Ebi KL, Frame DJ, Held H, Kriegler E, Mach KJ, Matschoss PR, Plattner GK, Yohe GW, Zwiers FW (2010) Guidance note for lead authors of the IPCC Fifth Assessment Report on Consistent Treatment of Uncertainties. Intergovernmental Panel on Climate Change (IPCC). Available at: http://www.ipcc.ch

Nigh GD (2006) Impact of climate, moisture regime, and nutrient regime on the productivity of Douglas-fir in coastal British Columbia, Canada. Clim Chang 76:321-337

Nordhaus W, Popp D (1997) What is the value of scientific knowledge? An application to global warming using the PRICE model. Energy J 18:1-45

Peterson S (2006) Uncertainty and economic analysis of climate change: a survey of approaches and findings. Environ Model Assess 11:1-17

Peyron JL, Terreaux JP, Calvet P, Guo B (1998) Principaux critères économiques de gestion des forêts: analyse critique et comparative. Ann For Sci 55:523-551

Piermont L (2007) Changement climatique: l'inflexion de sylviculture engagée par la Société Forestière de la Caisse des Dépôts. Rev Forest Fr 59:129-135

Plantinga AJ (1998) The optimal timber rotation: an option value approach. Forest Sci 44:192-202

Seidl R, Rammer W, Lexer MJ (2011) Adaptation options to reduce climate change vulnerability of sustainable forest management in the Austrian Alps. Can J Forest Res 41:694-706

Seppälä R, Alexander B, Katila P (2009) Adaptation of forests and people to climate change. A Global Assessment Report. IUFRO World Series 22, Helsinki

Shou E, Bredhal Jacobsen J, Lokke Kristensen K (2012) An economic evaluation of strategies for transforming even-aged into nearnatural forestry in a conifer-dominated forest in Denmark. Forest Policy Econ 20:89-98

Spiecker H (2000) Growth of Norway spruce (Picea abies [L.] Karst.) under changing environmental conditions in Europe. In: Klimo E, Hager H, Kulhavý J (eds) Spruce monocultures in Central Europe - problems and prospects. EFI Proceedings 33. European Forest Institute, pp 11-26

Spittlehouse DL, Stewart RB (2003) Adaptation to climate change in forest management. J Ecosystems Manag 4:1-11

Yousefpour R, Hanewinkel M, Le Moguedec G (2010) Evaluating the suitability of management strategies of pure Norway spruce forests in the Black Forest Area of Southwest Germany for adaptation to or mitigation of climate change. Environ Manage 45:387402

Yousefpour R, Jacobsen JB, Thorsen BJ, Meilby H, Hanewinkel M, Oehler K (2012) A review of decision-making approaches to handle uncertainty and risk in adaptive forest management under climate change. Ann For Sci 69:1-15 